\title{
Relative contribution of ammonia oxidizing bacteria and other members of nitrifying activated sludge communities to micropollutant biotransformation
}

Yujie Men $^{\mathrm{a}, \mathrm{b},{ }^{*}}$, Stefan Achermann ${ }^{\mathrm{a}, \mathrm{d}}$, Damian E. Helbling ${ }^{\mathrm{c}}$, David R. Johnson ${ }^{\mathrm{a}}$, Kathrin Fenner $^{\mathrm{a}, \mathrm{d}}$

${ }^{a}$ Eawag, Swiss Federal Institute of Aquatic Science and Technology, 8600 Dübendorf, Switzerland

${ }^{b}$ Department of Civil and Environmental Engineering, University of Illinois at UrbanaChampaign, Urbana, IL 61801, USA

${ }^{\mathrm{c}}$ School of Civil and Environmental Engineering, Cornell University, Ithaca, NY 14853, USA

${ }^{\mathrm{d}}$ Institute of Biogeochemistry and Pollutant Dynamics, ETH Zürich, 8092 Zürich,

Switzerland

* Corresponding author:

Yujie Men

Department of Civil and Environmental Engineering

University of Illinois at Urbana-Champaign,

Address: 3209 Newmark Civil Engineering Laboratory, MC-250

205 North Mathews Ave.

Urbana, IL 61801-2352, USA

Email: ymen2@illinois.edu

Phone: (217) 244-8259 


\begin{abstract}
Improved micropollutant (MP) biotransformation during biological wastewater treatment has been associated with high ammonia oxidation activities, suggesting co-metabolic biotransformation by ammonia oxidizing bacteria as an underlying mechanism. The goal of this study was to clarify the contribution of ammonia oxidizing bacteria to increased MP degradation in nitrifying activated sludge (NAS) communities using a series of inhibition experiments. To this end, we treated a NAS community with two different ammonia oxidation inhibitors, namely octyne (OCT), a mechanistic inhibitor that covalently binds to ammonia monooxygenases, and allylthiourea (ATU), a copper chelator that depletes copper ions from the active center of ammonia monooxygenases. We investigated the biotransformation of 79 structurally different MPs by the inhibitortreated and untreated sludge communities. Fifty-five compounds exhibited over $20 \%$ removal in the untreated control after a $46 \mathrm{~h}$-incubation. Of these, 31 compounds were significantly inhibited by either ATU and/or OCT. For 17 of the $31 \mathrm{MPs}$, the inhibition by ATU at 46h was substantially higher than by OCT despite the full inhibition of ammonia oxidation by both inhibitors. This was particularly the case for almost all thioether and phenylurea compounds tested, suggesting that in nitrifying activated sludge communities, ATU does not exclusively act as an inhibitor of bacterial ammonia oxidation. Rather, ATU also inhibited enzymes contributing to MP biotransformation but not to bulk ammonia oxidation. Thus, inhibition studies with ATU tend to overestimate the contribution of ammonia-oxidizing bacteria to MP biotransformation in nitrifying activated sludge communities. Biolog tests revealed only minor effects of ATU on the heterotrophic respiration of common organic substrates by the sludge community,
\end{abstract}


suggesting that ATU did not affect enzymes that were essential in energy conservation and central metabolism of heterotrophs. By comparing ATU- and OCT-treated samples, as well as before and after ammonia oxidation was recovered in OCT-treated samples, we were able to demonstrate that ammonia-oxidizing bacteria were highly involved in the biotransformation of four compounds: asulam, clomazone, monuron and trimethoprim.

\section{Keywords}

micropollutant; allylthiourea; octyne; ammonia-oxidizing bacteria; wastewater treatment plants; biotransformation 


\section{Introduction}

Micropollutants (MPs) such as pesticides, pharmaceuticals and personal care products (PPCPs) are increasingly detected in the environment and may adversely affect ecosystems and public health (Luo et al., 2014; Petrie et al., 2015). Extensive studies on MP biotransformation during the secondary biological treatment stage of WWTPs have revealed that many MPs were subject to partial removal, although biological treatment was not originally designed for MP removal (Pomies et al., 2013). Because only very few WWTPs are currently equipped with a tertiary treatment stage with the specific purpose of MP removal, such as advanced oxidation, the secondary treatment stage has a major effect on the mitigation of MPs before entering into the receiving environments. Therefore, a better understanding of the fate and transformation of MPs during biological wastewater treatment is of particular importance to evaluate the environmental impacts of both parent compound residues and transformation products (TPs).

A number of studies have pointed towards significant associations between MP biotransformation and nitrification activities of nitrifying activated sludge (NAS) in the biological treatment step. For example, biotransformation was enhanced for a variety of MPs, including pharmaceuticals, pesticides, and estrogens, as higher ammonia oxidation activities were reached in NAS (Fernandez-Fontaina et al., 2012; Helbling et al., 2012; Tran et al., 2009; Yi and Harper 2007). Based on these observations, a causal relationship has been widely hypothesized between ammonia oxidizers in NAS communities and the biotransformation of certain MPs. However, correlation does not necessarily equate to causation, and explicit tests of this hypothesis are needed. (Johnson et al., 2015b) 
Two controlled laboratory experimental approaches have typically been used to corroborate the importance of ammonia oxidizers for MP biotransformation: i) studies that test the MP biotransformation capabilities of pure cultures of different ammoniaoxidizing microorganisms (AOMs); and, ii) studies that investigate changes of MP biotransformation in NAS communities treated with inhibitors of ammonia oxidation. The biotransformation capabilities of AOMs for several MPs, such as mianserin and ranitidine (Men et al., 2016), triclosan and bisphenol A (Roh et al., 2009), p-cresol (Kjeldal et al., 2014), and estrogens (i.e., E1, E2, E3 and EE2) (Khunjar et al., 2011; Shi et al., 2004; Skotnicka-Pitak et al., 2009) have been demonstrated by pure culture studies, whereas no biotransformation activity has been observed in AOM pure cultures for compounds such as ibuprofen (Shi et al., 2004), trimethoprim (Khunjar et al., 2011), and eight other pesticides and pharmaceuticals (Men et al., 2016). These pure culture studies provide fundamental insights into biotransformation capability, reaction types and mechanisms, and the potential formation of TPs, but no concrete conclusion on MP biotransformation by AOMs in NAS communities can be drawn if negative results were obtained in the pure culture studies.

Inhibition studies are more used for understanding the contribution of AOMs to MP biotransformation in complex communities such as NAS. Given that most environmental microorganisms are uncultivable and tend to interact with other microbes in communities, pure culture studies may not always properly reflect the behavior of the microorganism in complex environmental microbial communities. In contrast, inhibition studies address the question of the actual role played by AOMs in a more environmentally relevant manner. 
Known AOM inhibitors include 1-alkynes $\left(\mathrm{C}_{2}-\mathrm{C}_{10}\right)$, which irreversibly inhibit ammonia monooxygenases (AMOs) (Hyman et al., 1988). Acetylene can inhibit both bacterial and archaeal AMOs, whereas octyne (OCT) was found to be more specific to ammonia-oxidizing bacteria (AOB) than to ammonia-oxidizing archaea (AOA). OCT has therefore previously been used to differentiate the roles played by AOB and AOA together with another inhibitor, PTIO, which is more specific to AOA (Martens-Habbena et al., 2015; Taylor et al., 2013). Besides acetylene and OCT, allylthiourea (ATU) is also considered a specific inhibitor of ammonia monooxygenases (AMOs), and has so far most commonly been used to investigate the linkage between MP biotransformation and nitrification (Batt et al., 2006; Khunjar et al., 2011; Li et al., 2015; Maeng et al., 2013; Rasche et al., 1991; Rattier et al., 2014; Roh et al., 2009; Sathyamoorthy et al., 2013; Tran et al., 2009; Zhou and Oleszkiewicz 2010). The biotransformation of a variety of MPs was affected by the addition of ATU to different extents, suggesting the involvement of AOMs. However, similar to OCT, ATU is not an effective inhibitor for AOA. ATU exhibited similar inhibitory effects as OCT on the nitrification in soil communities containing both ammonia-oxidizing bacteria (AOB) and archaea (AOA) (Taylor et al., 2013). In addition, the inhibitory effects of ATU on nitrification was incomplete (80\%) in archaea-containing seawater samples (Jantti et al., 2013). Therefore, ATU and OCT are more suitable for inhibition studies on NAS communities with AOMs dominated by AOB. For municipal WWTPs, the AOM in NAS communities are generally dominated by AOBs (Gao et al., 2013; Wells et al., 2009), although AOA have been found to be more abundant in some municipal and industrial WWTPs (Limpiyakorn et al., 2013; Sauder et al., 2012). 
However, there are two limitations for the inhibition studies conducted so far to address the contribution of AOMs to MP biotransformation. First, there is a lack of understanding how AOM-inhibitors interact with non-AOM members of complex microbial communities. This is because AOM-inhibitors have been primarily investigated in a biogeochemical context (i.e., focusing on the roles of different nitrifying microbial groups in the global $\mathrm{N}$ cycle) or in a biochemical context (i.e., focusing on roles of AMOs in pure or highly enriched cultures). Second, previous inhibition studies (Batt et al., 2006; Maeng et al., 2013; Margot et al., 2016; Rattier et al., 2014; Roh et al., 2009) only targeted a limited number of exposure-relevant, yet structurally diverse MPs, providing little information on the compound specificity of biotransformation performed by AOMs.

The goal of this study was to clarify the relative contribution of AOMs and other members of NAS microbial communities to MP biotransformation by specifically addressing the above-mentioned shortcomings of previous inhibition studies. To address questions of compound specificity, we used a total of 79 MPs for the inhibition study, which were selected to cover different chemical classes and/or groups of anticipated biotransformation reactions with multiple compounds in each of the selected categories. To address questions of inhibitor specificity, we compared the biotransformation of selected MPs with or without the addition of two inhibitors (i.e., ATU and OCT) in a previously studied NAS community in which AOB were supposed to be the dominant group of AOMs (Men et al., 2016). The effects of ATU on heterotrophic respiration were investigated to further examine the specificity of ATU. Overall, we sought to provide a 
comprehensive view of the biotransformation of the tested MPs in NAS, and more specifically, the extent to which AOB are involved in their biotransformation.

\section{Materials and Methods}

\subsection{Compound selection}

A total of 79 MPs (Table S1) were selected based on compound availability and to have multiple compounds cover the same chemical classes and/or anticipated biotransformation reactions. The reference compounds for the 79 MPs were purchased from Sigma-Aldrich Chemie GmbH (Buchs, Switzerland), Dr. Ehrenstorfer GmbH (Augsburg, Germany), HPC Standards GmbH (Cunnersdorf, Germany), Honeywell Specialty Chemicals (Seelze, Germany), and Toronto Research Chemicals (Toronto, Canada). Stock solutions were prepared in ethanol, with a concentration of $40-50 \mathrm{mg} / \mathrm{L}$ for each compound. Allylthiourea (ATU) and 1-octyne (OCT) were purchased from Sigma-Aldrich Chemie GmbH (Buchs, Switzerland).

\subsection{Inhibition experiments}

The inhibition experiments were performed in batch reactors. Nitrifying activated sludge (NAS) was taken from the aeration tank of a Swiss municipal WWTP with a TSS of 2.2 g/L. Fifty mL NAS were inoculated into 155-mL glass bottles. One mL of ATU stock solution ( $1 \mathrm{~g} / \mathrm{L}$ in nanopure water) or $2.5 \mu \mathrm{L}$ of neat OCT were added into each bottle, resulting in initial concentrations of $20 \mathrm{mg} / \mathrm{L} \mathrm{ATU} \mathrm{(ca.} 170 \mu \mathrm{M}$, and two times as much as the reported effective concentration for instantaneous complete inhibition) (Ginestet et al., 1998) or of $4.2 \mathrm{mg} / \mathrm{L}$ OCT (c.a. $38 \mu \mathrm{M}$ aqueous concentration, and $\sim 8$ times as much as the reported effective concentration for instantaneous inhibition for AOB strains

Nitrosomonas europaea and Nitrosospira multiformis) (Taylor et al., 2013), respectively. 
Bottles without inhibitor treatment were established as controls. To prevent OCT volatilization and for better comparability, all bottles were sealed by screw caps with rubber septa. The bottles were pre-incubated by shaking at $160 \mathrm{rpm}$ at room temperature for $6 \mathrm{~h}$ to allow for effective inhibition of OCT on ammonia oxidation. To be comparable, ATU-treated and control bottles were also sealed and pre-incubated in the same way as OCT-treated ones. A volume of $50 \mu \mathrm{L}$ of the MP stock solution $(8 \mathrm{mg} / \mathrm{L}$ for each compound) was added into $100-\mathrm{mL}$ empty glass batch reactor bottles to finally yield initial concentrations of $8 \mu \mathrm{g} / \mathrm{L}$ for each compound. The solvent (i.e., ethanol) was allowed to evaporate in a fume hood with gentle air circulation for approximately $10 \mathrm{~min}$. Finally, $50 \mathrm{~mL}$ of the aforementioned pre-incubated inhibitor-treated or untreated NAS sample were inoculated into the reactor bottles and incubated at room temperature without the addition of ammonium. Triplicates were performed for ATU- and OCTtreated reactors, as well as for the untreated control. To avoid dissolved oxygen (DO) limitation, all experimental reactor bottles were capped with two-hole caps and incubated with shaking at $160 \mathrm{rpm}$. The DO was above $5 \mathrm{mg} / \mathrm{L}$ during the entire incubation period. After allowing the plated MPs re-dissolve for $30 \mathrm{~min}, 1 \mathrm{~mL}$ sludge samples from each reactor were taken as $0 \mathrm{~h}$ samples. Subsequent samples were taken at 2, 4, 6, 10, 18, 24, $46,70,120$, and $144 \mathrm{~h}$. The sludge samples were centrifuged at $13,000 \mathrm{rpm}$ at room temperature for $10 \mathrm{~min}, 500 \mu \mathrm{L}$ of the supernatant was transferred into a $2 \mathrm{~mL}$ amber glass HPLC vial, amended with $20 \mu \mathrm{L}$ internal standard mix (50 $\mu \mathrm{g} / \mathrm{L}$ of each internal standard in the mix (see Table S1) ) and stored at $4{ }^{\circ} \mathrm{C}$ in the dark until LC-MS/MS analysis (maximally 6-day storage before analysis). 
Reactors for measurement of the organic carbon utilization rate (CUR) and ammonia utilization rate (AUR) were set up separately, with $50 \mathrm{~mL}$ of the same inhibitortreated or untreated sludge samples but without MP addition. For CUR reactors, sodium acetate (ca. $50 \mathrm{mg} / \mathrm{L} \mathrm{COD)}$ ) was added at 1 and $24 \mathrm{~h}$ without the addition of ammonium. For AUR reactors, ammonium chloride $(10 \mathrm{mg} / \mathrm{L})$ was added to all ATU- and OCTtreated reactors and the untreated control reactor at $0 \mathrm{~h}$ and only to the untreated control reactor at $70 \mathrm{~h}$, since there was still ammonium in ATU- and OCT- treated reactors. One $\mathrm{mL}$ sludge samples were taken at subsequent time points at 0.5 or $1 \mathrm{~h}$ intervals until $2 \mathrm{~h}$, and filtered through $0.7 \mu \mathrm{m}$ glass fiber filters. The flow-through was collected and subject to $\mathrm{COD}, \mathrm{NH}_{4}-\mathrm{N}$, and $\mathrm{NO}_{3}-\mathrm{N}$ measurement using Hach Lange test tubes and a Hach Lange Spectrometer (Hach Lange GmbH, Rheineck, Switzerland) according to the manufacturer's instructions. Additional samples at 11, 24, 46, 120, and $144 \mathrm{~h}$ were also taken for $\mathrm{NH}_{4}-\mathrm{N}$, and $\mathrm{NO}_{3}-\mathrm{N}$ measurement. The $\mathrm{pH}$ was monitored every other day with a pH meter (Hach Lange GmbH).

Abiotic transformation and sorption of the MPs to heat-inactivated sludge were investigated in a separate batch experiment using the same setup in triplicate, except that instead of inoculating inhibitor-treated or untreated sludge samples, autoclaved $\left(121{ }^{\circ} \mathrm{C}\right.$ for $20 \mathrm{~min})$ sludge filtrate $(0.2 \mu \mathrm{m}$ sterile regenerated cellulose filter) was used for abiotic transformation experiments, and unfiltered, autoclaved sludge was used for sorption experiments. Samples for LC-MS/MS were taken once at $2 \mathrm{~h}$ for the sorption experiments, since physical sorption to sludge is known to occur fast (i.e., typically within 2h) (Dorival-Garcia et al., 2013; Gulde et al., 2014; Li and Zhang 2010; Yang et 
al., 2012). For the abiotic transformation experiments, samples were taken at $0 \mathrm{~h}, 1,2$, and $3 \mathrm{~d}$.

\subsection{LC-MS/MS analysis}

Compound concentrations were analyzed by reversed phase liquid chromatography coupled to a high-resolution quadrupole orbitrap mass spectrometer (LC-MS/MS) (QExactive, Thermo Fisher Scientific Corporation, San Jose, US). For HPLC, $100 \mu \mathrm{L}$ sample was loaded onto an Atlantis-T3 column (particle size $3 \mu \mathrm{m}, 3.0 \times 150 \mathrm{~mm}$, Waters). The mobile phase consisted of nanopure water (Barnstead Nanopure, Thermo Scientific) and methanol (HPLC-grade, Fisher Scientific), both augmented with $0.1 \%$ formic acid (98-100\%, Merck), at a flow rate of $300 \mu \mathrm{L} / \mathrm{min}$. The initial condition (95:5 water/methanol) was held for $1 \mathrm{~min}$, then increased to 5:95 water/methanol over $16 \mathrm{~min}$, and held for $8 \mathrm{~min}$. It was then set back to the initial condition over $0.1 \mathrm{~min}$, held for 4.9 min for column conditioning before the next analysis. Electrospray ionization was triggered at a capillary temperature of $320^{\circ} \mathrm{C}$ and a spray voltage of $+4 \mathrm{kV}$ in positive ionization mode and $-3 \mathrm{kV}$ in negative ionization mode. To enhance the calibration for small masses, a mass calibration and mass accuracy check was performed prior to the measurement with an in-house amino acid solution. Mass accuracy was always better than $1.5 \mathrm{ppm}$. The compounds were measured in full scan mode at a resolution of 140,000 at $200 \mathrm{~m} / \mathrm{z}$ and a scan range of $50-750 \mathrm{~m} / \mathrm{z}$ in positive/negative switching mode. Calibration curves were established in nanopure water using standard series ranging between 0.05 and $10 \mu \mathrm{g} / \mathrm{L}$ with $2 \mu \mathrm{g} / \mathrm{L}$ internal standards (Table S1). The lowest quantitative $(80 \%<$ accuracy $<120 \%)$ calibration point of $0.1 \mu \mathrm{g} / \mathrm{L}$ was regarded as the limit of quantification (LOQ). 


\subsection{Biolog analysis}

Effects of ATU on the heterotrophic respiration of NAS were examined by Biolog Test (Biolog, Hayward, CA). As OCT is volatile, the Biolog test is not suitable to investigate its influence on heterotrophic respiration. Additionally, since only 3 MPs exhibited higher inhibition in the OCT-treated samples than in the ATU-treated ones, this study focused on the effect of ATU on heterotrophic respiration. Two replicates of $40 \mathrm{~mL}$ NAS samples in conical centrifuge tubes were homogenized by sonication for 10 s. Sludge cells were collected by centrifugation at $4000 \mathrm{rpm}$ at room temperature for $2 \mathrm{~min}$, washed twice and re-suspended with $40 \mathrm{~mL} 0.8 \% \mathrm{NaCl}$ solution. Large sludge aggregates were separated by low speed centrifugation (1000 rpm at room temperature for $2 \mathrm{~min}$ ). The suspended sludge cells in the supernatant were adjusted to an optical density at $590 \mathrm{~nm}$ $\left(\mathrm{OD}_{590}\right)$ of 0.8 and then collected by centrifugation at $5000 \mathrm{rpm}$ for $5 \mathrm{~min}$ at room temperature. The collected sludge cells in each tube were re-suspended in $12.5 \mathrm{~mL}$ IF-A incubating fluid (Biolog, Hayward, CA). One was amended with ATU (initial concentration $20 \mathrm{mg} / \mathrm{L}$ ), and the other served as an untreated control. The Biolog GEN III micro plate (Biolog, Hayward, CA) targets carbon utilization activity of 71 different carbon sources and sensitivity to 23 chemical stresses (e.g., $\mathrm{pH}$, salinity and antibiotics). Tetrazolium redox dyes contained in the IF-A incubating fluid were used to colorimetrically indicate utilization of the carbon sources or resistance to inhibitory chemicals. Carbon sources or inhibitory chemicals were pre-supplied by the manufacturer, one per well, and the detailed layout of carbon sources and chemical stresses can be found in the manufacturer's manual (http://www.biolog.com/). In each well, $100 \mu \mathrm{L}$ of sludge cell suspension treated with or without ATU (one plate for each 
condition) was inoculated. The plates were incubated at $25^{\circ} \mathrm{C}$ with continuous shaking in a plate reader (BioTek Instruments GmbH, Luzern, Switzerland). The heterotrophic respiration activity in each well was determined by measuring $\mathrm{OD}_{590}$, which was automatically measured every 30 min over a time course of $36 \mathrm{~h}$. The lagtime and the maximum respiration rate of sludge cells in each well were calculated by Gen5 data analysis software that comes with the BioTek microplate reader. Each individual well was taken as one replicate sample for the 71 carbon sources or 23 chemical stresses. The statistical difference of overall carbon utilization with or without chemical stresses between ATU-treated and untreated samples was analyzed by student t-test $(p<0.05)$.

\subsection{Determination of the extent of inhibition}

Only compounds without strong sorption effect ( $<30 \%$ removal in sorption control) and abiotic transformation ( $<30 \%$ removal in abiotic control) were subject to further analysis. To quantify the inhibition effects of ATU and OCT, the extent of inhibition at time $\mathrm{t}\left(I_{t}\right)$ relative to the control reactors were determined according to the following equation.

$I_{t}=\frac{R_{t, c t r l}-R_{t, \text { treated }}}{R_{t, c t r l}}$

where $R_{t}$ is the average relative removal $\left(1-C_{t} / C_{0}\right)$ of triplicate reactors at time $t$.

As ammonia oxidation activity was recovered in OCT-treated samples after $46 \mathrm{~h}$, we calculated the extent of inhibition using the time points up until 46 h. For compounds that were completely removed before $46 \mathrm{~h}$, we only used the time points when MP concentrations > LOQ. 
The statistical significance of difference of removals between ATU- and OCTtreated samples was calculated using student t-test with Benjamini and Hochberg procedure to control the false discovery rate $<0.05$ (Benjamini and Hochberg 1995).

\section{Results}

\subsection{Inhibitory effects of ATU and OCT on ammonia oxidation}

ATU and OCT completely inhibited ammonia oxidation in the NAS communities during the first $46 \mathrm{~h}$, as demonstrated by nearly constant $\mathrm{NO}_{3}-\mathrm{N}$ and increasing $\mathrm{NH}_{4}-\mathrm{N}$ caused by cell decay in ATU- and OCT- treated reactors (Fig. S1). However, after 46 h, in OCTtreated reactors, the ammonia oxidation activity partially recovered (AUR $>0)$ at $70 \mathrm{~h}$ (Table S2), after which the $\mathrm{NH}_{4}-\mathrm{N}$ concentration substantially decreased with the corresponding formation of nitrate (Fig. S1). In contrast, no ammonia oxidation activity was observed in the ATU-treated reactors over the entire incubation period of $144 \mathrm{~h}$ (Fig. S1). The recovery of ammonia oxidation activity in OCT-treated samples was most likely because of the synthesis of new AMO enzymes in the inhibited cells after a lag time under a decreased OCT stress caused by volatilization of OCT in the open reactors. The differential ammonia oxidation activities in ATU- and OCT-treated reactors were also revealed by the $\mathrm{pH}$ profile in the treated and untreated reactors (Fig. S2). While the $\mathrm{pH}$ in the ATU-treated reactor increased to a stable level of around 8.6, the $\mathrm{pH}$ in the untreated reactor continuously decreased due to nitrification. The $\mathrm{pH}$ in the OCT-treated reactors increased first, but after a peak at $70 \mathrm{~h}$, it decreased substantially to levels similar to those in the untreated reactor (Fig. S2). Therefore, for the following analyses, we assume that before $46 \mathrm{~h}$ ammonia oxidation was completely inhibited in both ATU- and OCT-treated reactors, whereas after $46 \mathrm{~h}$ the activity of ammonia oxidizers gradually recovered in 
OCT-treated, but not in ATU-treated reactors. Comparison of MP biotransformation activities in ATU- and OCT- treated reactors before and after $46 \mathrm{~h}$ will thus further help elucidate the contribution of AOB to MP biotransformation.

\subsection{Different inhibition effects of ATU and OCT on MP biotransformation}

In the control reactors without inhibitor addition, 55 out of the 79 MPs were biotransformed by NAS with average removals $>20 \%$ at 46 h (Fig. 1 \& Fig. S3), while 20 compounds were more persistent $(<20 \%$ removal), including four triazine herbicides (atrazine, cyromazine, simeton, terbutylazine) and two compounds (dicamba and mecoprop) containing an alkyl-aryl ether as the main functional group. Three compounds (fenoxycarb, fluoxetine and ticlopidine) were strongly sorbed (> 30\% removal in the sorption control), and one compound (kresoxim-methyl) was subject to abiotic degradation (> 30\% removal in the abiotic control). Of the 55 biotransformed compounds that were further analyzed, 31 showed an extent of inhibition $I_{46 h}>0.2$ in either ATU- or OCT-treated reactors, whereas minimal $\left(I_{46 h}<0.2\right)$ to no inhibition of biotransformation was observed for the other 24 compounds. Biotransformation of phenylureas and compounds containing thioether and amidine functional groups was consistently inhibited by ATU and/or OCT (Fig. 1). Those compounds are known to often primarily undergo oxidation reactions such as oxidative dealkylation, deamination, or N-/S-oxidation (Auret et al., 1973; Helbling et al., 2012; Hlavica and Damani 1991). In contrast, esters and chloroacetanilides, which typically undergo hydrolysis or other substitution reactions, were not or only slightly affected by ATU or OCT (Fig. 1).

Notably, for 17 out of the 31 inhibited MPs, the inhibition was more than 1.5 times higher with ATU than with OCT (i.e., $I_{A T U, 46 h}: I_{O C T, 46 h}>1.5$ ) (Fig. 2). The 
removals in ATU-treated and OCT-treated reactors were also statistically significantly different according to student t-test with Benjamini and Hochberg procedure (FDR < 0.05 ) for 10 out of the 17 compounds (Fig. 2). Higher inhibition by ATU was observed for all three compounds containing a thioether functional group and three out of five biotransformed phenylureas. In contrast, OCT resulted in stronger inhibition than ATU (i.e., $I_{O C T, 46 h}: I_{A T U, 46 h}>1.5, \mathrm{FDR}<0.05$ ) for only $3 \mathrm{MPs}$ (i.e., capecitabine, N,Ndimethyl-4-chlorobenzamide and N-butyl-N-ethyl-4-chlorobenzamide). Similar inhibition (i.e., $0.7<I_{A T U, 46 h}: I_{O C T, 46 h}<1.5$, and FDR $>0.05$ ) by ATU and OCT was observed for the remaining 11 compounds with unclear compound specificity (Fig. 3).

According to ATU specificity, we divide microorganisms that contributed to MP biotransformation in the NAS community into three groups: i) AOB, ii) non-AOB microorganisms carrying ATU-affected enzymes, and iii) non-AOB microorganisms not affected by ATU. Thus, from the extents of inhibition by ATU and OCT, we are able to determine how much of the biotransformation of each compound could potentially be associated with those three groups. Non-AOB microorganisms carrying ATU-affected enzymes substantially contributed to the total removal of chlortoluron, amisulpride, carbendazim, and tebufenozide. Both $\mathrm{AOB}$ and non-AOB microorganisms carrying ATU-affected enzymes contributed together $>70 \%$ to the total removal of diuron, furosemide and indomethacin. The biotransformation of the other 10 compounds with higher inhibition by ATU than by OCT was overall mostly by non-AOB microorganisms not affected by ATU (Fig. 2). It is worth noting that, of the five tested sulfonamide antibiotics (i.e., sulfadiazine, sulfamethazine, sulfamethoxazole, sulfapyridine and sulfathiazole), only sulfathiazole biotransformation was more inhibited by ATU than by 
OCT, whereas the biotransformation of the other sulfonamides was not inhibited by ATU or OCT (Fig. 1 and 2).

For all 11 compounds with similar extents of inhibition by ATU and OCT (i.e., $0.7<I_{A T U}: I_{O C T}<1.5$ and no statistical significance $($ FDR $<0.05)$ between removals of ATU- and OCT-treated samples), the inhibition by OCT decreased when ammonia oxidation recovered in OCT-treated reactors, whereas the inhibition by ATU was retained (Fig. 3). This further corroborates that $\mathrm{AOB}$ contributed to the biotransformation of the 11 compounds. Non-AOB microorganisms not affected by ATU also contributed importantly to the biotransformation of seven of them, as the inhibition by OCT for these compounds was less than 50\%. In contrast, the contribution of $\mathrm{AOB}$ to the biotransformation of the other four compounds (i.e., asulam, clomazon, monuron and trimethoprim) was essential, given the high inhibition (50 - 90\%) at $46 \mathrm{~h}$ in OCT-treated samples, and the restoration of biotransformation to similar levels as in the untreated control after $70 \mathrm{~h}$ (Fig. 4).

\subsection{Effects of ATU on heterotrophic respiration}

To investigate the effects of ATU on heterotrophs in the NAS community, we first looked at the COD removal in ATU-treated and untreated reactors. The COD removal rates were similar, although with a slight decrease in the ATU-treated sample at $24 \mathrm{~h}$ (Fig. S4). Furthermore, we conducted Biolog plate tests to compare the heterotrophic respiration of 71 carbon sources, and the sensitivities to 23 chemical stresses by NAS treated with ATU and the untreated control. Two parameters, the lag time and the maximum carbon source utilization rate, were used to assess heterotrophic growth. The overall effect of ATU on respiration and chemical sensitivity of heterotrophs can then be 
represented by changes in these two parameters under all carbon source and chemical stress conditions. Student's t-test was applied to determine whether the ratio of ATUtreated to untreated samples was significantly different from 1 . For carbon utilization, the difference of the lag time between ATU-treated and untreated samples was statistically significant $(p=0.05, \mathrm{n}=71)$ with an average ratio of 0.96 (ATU-treated to -untreated) (Fig. S6A). There was also a statistically significant difference for the maximum utilization rate $(p=0.03, \mathrm{n}=71)$ with an average ratio of 0.91 between ATU-treated and untreated samples. The utilization of six carbon sources was negatively affected by ATU with the treated-to-untreated ratio below 0.5 , while the utilization of one carbon source was enhanced by ATU with a treated-to-untreated ratio of the maximum utilization rate above 2 (Fig. S6B). Regarding the chemical sensitivity, no statistically significant difference was noted in terms of the lag time $(p=0.08, \mathrm{n}=23$, average treated-tountreated ratio of 0.98 ), whereas the maximum utilization with ATU treatment rate was slightly higher (average treated-to-untreated was 1.14) with statistical significance ( $p=$ 0.007, $\mathrm{n}=23)($ Fig. S6C \& D).

\section{Discussion}

\subsection{Compound specificity of ATU-affected, non-AMO enzymes in MP biotransformation}

In this study, both ATU and OCT completely inhibited nitrification activities in a NAS community during a 46-h incubation period. However, ATU exhibited stronger inhibition on the biotransformation of $17 \mathrm{MPs}$, whereas OCT showed stronger inhibition effects for only three MPs. Given that the OCT concentration used in this study was in higher excess compared to the effective concentration than the ATU concentrations used, the stronger inhibition by ATU is unlikely due to a concentration effect. Rather it suggests that ATU 
is less specific than OCT for bacterial AMOs, inhibiting additional enzymes that were associated with the biotransformation of the 17 MPs.

Interestingly, these ATU-affected enzymes other than AMO seem to have some compound specificity, as higher inhibition by ATU was observed for all compounds containing a thioether functional group, as well as for three of the five tested phenylurea herbicides. The compound specificity for thioethers even extended to the tested sulfonamide antibiotics. Sulfathiazole biotransformation was partially inhibited by ATU but hardly by OCT, whereas no inhibition effect was observed for the other four sulfonamides. The major difference between the structure of sulfathiazole and the other sulfonamides is the thiazole group, which includes a thioether-like structure in a cyclic ring (Fig. S5). This suggests that the thioether functional group and the thioether-like structure in the thiazole group were the active sites of the biotransformation reactions occurring for the three thioethers and sulfathiazole. Interestingly, we detected the $\mathrm{N}_{4^{-}}$ acetyl conjugation TPs for four sulfonamides (i.e., sulfadiazine, sulfamethazine, sulfamethoxazole, and sulfapyridine) but not for sulfathiazole (Fig. S7). Although the detected $\mathrm{N}_{4}$-acetyl sulfonamides were all at low levels $(<10 \%$ of the parent compounds and subject to further transformation), this observation supports, at least partially, a differing biotransformation behavior of sulfathiazole. Nevertheless, another compound, thiacloprid, which also contains a thioether functional group did not show differential inhibition effects of ATU (Fig. 3). One possible reason is that the main biotransformation reactions for this compound occurred at other functional groups such as the cyanamide or amidine group. However, this still remains speculative as the TPs are unknown. Besides 
the thioether and phenylurea groups, no other clear compound specificity could be recognized.

\subsection{Possible ATU-affected enzymes in NAS}

One class of ATU-affected enzymes other than bacterial AMOs could be archaeal AMOs. Although AOA showed higher tolerance to $100 \mu \mathrm{M}$ ATU (Jantti et al., 2013), ATU may still partially inhibit archaeal AMOs given the higher ATU concentration $(170 \mu \mathrm{M})$ used in this study than that used by Jantti et al. Although full inhibition of nitrification was achieved with both OCT and ATU-treatment, and AOA thus seemed to have contributed little to ammonia oxidation in the investigated NAS community, archaeal AMOs might still have contributed to MP biotransformation if they had much higher affinities for MPs than for ammonia. However, given that in a previous inhibition study with NAS samples taken from the same WWTP, the AOA-specific inhibitor PTIO only inhibited ranitidine biotransformation by 5\% (Men et al., 2016), while in this study the inhibition effect of ATU was 30\%, the differential inhibition of ranitidine biotransformation by ATU and OCT was less likely to be solely due to archaeal AMOs.

Candidates for ATU-affected enzymes other than AMOs can be derived from the inhibition mechanism of ATU. ATU inhibits AMOs by chelating copper ions that serve as the essential metal center of the enzyme (McCarty 1999). According to this mode of action, ATU-affected enzymes other than AMOs could be other copper-containing enzymes. Enzymes homologous to bacterial AMOs such as particulate methane monooxygenases (pMMOs) in ammonia-oxidizing aerobic methanotrophs and particulate butane monooxygenases (pBMOs) in butane-oxidizing bacteria usually have a copper center (Balasubramanian et al., 2010; Sayavedra-Soto et al., 2011). OCT has also been 
shown to be a mechanistic inhibitor of alkane monooxygenases in Pseudomonas putida (Alonso and Roujeinikova 2012). Besides these AMO homologs, other examples of copper-containing enzymes include amine oxidases, copper-containing nitrite reductases/multicopper oxidases, CuZn superoxide dismutases, tyrosinases, and laccases, all of which are ubiquitously found in a large range of organisms including prokaryotes (MacPherson and Murphy 2007; Rosenzweig and Sazinsky 2006). Gene transcripts of the above-mentioned copper enzymes were searched in the metatranscriptome of a NAS sample taken from the same WWTP (Johnson et al., 2015a), and those of coppercontaining nitrite reductases that present in a variety of metabolically diverse bacteria, were detected with comparable abundance to those of bacterial AMOs. This suggests that copper-containing nitrite reductases are candidates for ATU-affected enzymes in microorganisms other than AOB that contributed to the biotransformation of certain MPs.

\subsection{Effects of ATU on heterotrophic respiration}

Previously, the specificity of ATU to ammonia oxidizers was evaluated based on its effects on heterotrophic respiration of organic carbon. ATU was considered to be specific to ammonia oxidizers as no effect on dissolved organic carbon (DOC) removal was observed (Zhou and Oleszkiewicz 2010). Our results confirm that COD removal rates in ATU-treated samples were similar to the untreated control and the overall carbon utilization on a Biolog plate was only slightly ( 10\%) affected by ATU. The addition of ATU seemed to stimulate carbon utilization under chemical stresses. Meanwhile, some researchers questioned the specificity of ATU as they observed a decrease of DOC removal (Maeng et al., 2013; Rattier et al., 2014). According to Maeng et al., 25\% removal of low molecular weight neutral organic carbons (accounting for $15 \%$ of the 
total removal) was affected by ATU. We observed that ATU affected heterotrophic utilization of 6 carbon sources on the Biolog plate by more than a factor of 1.5 , all of which were small organic acids. However, drawing concrete conclusions on the effects of ATU on the utilization of individual carbon sources from our study is difficult because of the lack of replicates for each of the carbon sources. Taken together, the effects of ATU on the overall heterotrophic respiration were minor. Yet, MP biotransformation results in this study clearly suggest that ATU is not specific to bacterial AMO. Therefore, we can conclude that the ATU-affected enzymes unrelated to AMOs but associated with MP biotransformation were most likely not essential for central metabolism or energy conservation.

\subsection{A comprehensive comparison with results of ATU inhibition studies in literature}

The overlooked nonspecific inhibition by ATU in complex microbial communities will result in an overestimation of the contribution of AOB to MP biotransformation in NAS communities, thus misleading the conclusions generated from ATU inhibition studies. In our study, $56 \%$ of the biotransformed MPs exhibited an extent of inhibition $>0.2$ with ATU-treatment, but only $38 \%$ actually showed an extent of inhibition $>0.2$ with OCTtreatment. To examine the potential misinterpretation in previously reported ATU inhibition studies, we comprehensively summarized the MPs, for which ammonia oxidizers have been hypothesized to play an important role based on evidence from such studies. We compared these previous findings with the results for the MPs also investigated in this study (Table 1). ATU inhibition effects were consistent for most MPs shared among different studies, regardless of different experimental conditions (e.g., the concentrations of ATU, biomass, and MPs). For instance, ibuprofen biotransformation 
was consistently found to be not or only slightly affected by ATU treatment (Falas et al., 2012; Margot et al., 2016; Roh et al., 2009; Tran et al., 2009), in agreement with our finding that its biotransformation was mainly carried out by ATU-insensitive, most likely heterotrophic enzymes. For six MPs (i.e., ketoprofen, furosemide, indomethacin, diclofenac, irgarol, and terbutyn) (Table 1), different studies consistently indicated that their biotransformation was inhibited by ATU, and hence AOB were concluded to play an important role (Maeng et al., 2013; Margot et al., 2016; Rattier et al., 2014; Tran et al., 2009). However, according to our results, the contribution of AOB to their biotransformation seems to be overstated because the biotransformation inhibition was $1.5-2.5$ times higher by ATU than by OCT. Thus, about half of the biotransformation previously attributed to AOB might be actually carried out by ATU-affected enzymes, most likely from hetrotrophs. In addition, the non-specificity of ATU also weakens conclusions drawn for the other MPs in Table 1 that were not included in this study. Based on our findings, whether and to what extent AOB were involved in the biotransformation of those MPs becomes inconclusive. Except for the compounds containing a thioether or phenylurea functional group, no clear compound specificity could be observed for the stronger biotransformation inhibition effects by ATU than by OCT. It is thus difficult to refine conclusions of previous ATU inhibition studies based on compound structures only. Therefore, we suggest that more specific inhibitors (OCT in this case) should be used in future inhibition studies to more precisely characterize the relative contribution of ammonia oxidizers to MP biotransformation.

By comparing inhibition in ATU- and OCT-treatments, as well as the biotransformation activities before and after ammonia oxidation activity recovered in 
OCT-treated samples, we were able to confirm the contribution of AOB to the biotransformation of a number of MPs, including isoproturon and napropamide that were not biotransformed by AOA or AOB pure cultures according to our previous pure culture study (Men et al., 2016). This indicates that inhibition studies can provide additional insights into the relevance of ammonia oxidizers in the biotransformation of MPs that were not biotransformed in pure culture studies. Moreover, this study revealed a major contribution ( $\sim 50-90 \%$ of the total removal) of AOB to the biotransformation of asulam, clomazone, monuron, and trimethoprim. However, discrepancies exist among different studies regarding the biotransformation of trimethoprim. Our results suggest that AOB and other microorganisms with enzymes not affected by ATU or OCT contributed to $60 \%$ and $40 \%$ of the total removal of trimethoprim, respectively. This is consistent with the findings of Batt et al. (2006) (Table 1). However, no ATU inhibition on trimethoprim biotransformation was observed in two other studies (Khunjar et al., 2011; Rattier et al., 2014). Khunjar et al. (2011) also detected two major TPs (m/z 221 and m/z 183) during trimethoprim biotransformation in heterotrophic reactors, in which nitrification was inhibited. This inconsistency is likely due to a shift in actively occurring transformation reactions influenced by different environmental conditions such as redox conditions and initial MP concentrations. Indeed, high and low initial concentrations of trimethoprim have been reported to result in different TP formation profiles (Jewell et al., 2016). We therefore screened for the reported trimethoprim TPs in our samples using suspect screening with LC-HRMS data (Helbling et al., 2010), and found no evidence for the presence of the two TPs found by Khunjar et al. (2011) during the biotransformation by heterotrophs (data not shown), indicating that different biotransformation reactions 
occurred in our study. Interestingly, inconsistency regarding anoxic/anaerobic removals of trimethoprim (higher or lower than aerobic removals) were also observed among studies (Burke et al., 2014; Falas et al., 2016), further suggesting that trimethoprim may undergo various biotransformation pathways carried out by different microbial groups, which can be substantially affected by environmental conditions. Similarly, the inconsistent ATU inhibition effects on the biotransformation of naproxen between our study and two other studies (Table 1) may also be due to the involvement of multiple microbial groups as the inhibition by ATU was not complete according to the other two studies (Margot et al., 2016; Tran et al., 2009).

Additionally, the microbial abundance may significantly affect actual biotransformation reactions. In the investigated NAS community, we found that AOB only played a minor role in the biotransformation of sulfamethoxazole, whereas in an AOB enrichment from another study, AOB were found to be highly involved in the biotransformation of sulfamethoxazole, leading to the formation of the 4-nitro TP (Kassotaki et al., 2016). Different from the NAS community, the AOB enrichment was dominated by $\mathrm{AOB}(>80 \%)$ and nitrite was accumulated with no further oxidation to nitrate. Since abiotic nitritation was not fully excluded by control experiments at the experimental temperature, the 4-nitro TP may have been formed from nitritation, which is highly dependent on nitrite availability and hence ammonia oxidation activity. AOBmediated nitritation was previously demonstrated for EE2 (Sun et al., 2012). Nitro TPs of sulfamethoxazole were not detected in our study according to suspect screening (data not shown), indicating different biotransformation pathways, which were more likely carried out by enzymes not affected by ATU and most likely from heterotrophs. Collectively, the 
actual roles played by ammonia oxidizers may vary depending on community composition and environmental conditions. TP analysis is helpful to further confirm the roles played by different community members. However, there are challenges for TP identification in complex systems without reference compounds, and a comprehensive TP analysis was therefore out of the scope of this study.

At last, we acknowledge that the involvement of different community members in MP biotransformation revealed by inhibition studies could be either direct (i.e., the inhibited microorganisms/enzymes were responsible for the biotransformation) or indirect (i.e., the microorganisms possessing the responsible enzymes were highly dependent on the actually inhibited microorganisms). One example for such possible indirect involvement are nitrite-oxidizing bacteria (NOB) that live "syntrophically" with ammonia oxidizers. Their contribution to MP biotransformation should therefore also be studied, in order to differentiate from the roles played by ammonia oxidizers.

\section{Conclusions}

- The inhibitory effect of ATU in a complex microbial community such as NAS is not as exclusive to ammonia oxidizers as thought previously. Using ATU in complex communities will likely also inhibit non-AMO enzymes in microorganisms other than $\mathrm{AOB}$, leading to a potential overestimation of the contribution of ammonia oxidizers to MP biotransformation.

- Microorganisms with ATU-affected enzymes other than ammonia oxidizers were even more important for the biotransformation of certain MPs according to our findings. Based on several lines of reasoning, we suggest that these enzymes were likely copper-containing enzymes not critical for heterotrophic respiration. 
- Future inhibition studies on complex communities should pay closer attention to inhibitor specificity, and more specific inhibitors like 1-alkynes should be used instead of or alongside ATU as a complementary approach to pure culture studies.

- Using OCT, we found robust evidence for the involvement of AOB in the biotransformation of a number of MPs.

- Analyzing TPs from the inhibition experiments can help further associate biotransformation pathways to specific community members.

\section{Acknowledgements}

We would like to give our thanks to Andreas Maccagnan and Birgit Beck at Eawag and all contact persons at ARA Wueeri in Regensdorf, Switzerland, for the NAS sampling assistance, to Dr. Cresten Mansfeldt for his kind help with thoughtful discussion and manuscript review. We acknowledge the support from the Swiss National Science Foundation (SNF project number CR23I2_140698) and from the European Research Council under the European Union's Seventh Framework Programme (ERC grant agreement no. 614768, PROduCTS).

\section{References}

Alonso, H. and Roujeinikova, A., 2012. Characterization and two-dimensional crystallization of membrane component AlkB of the medium-chain alkane hydroxylase system from Pseudomonas putida GPo1. Appl. Environ. Microbiol. 78(22), 7946-7953. 
Auret, B.J., Boyd, D.R., Henbest, H.B. and Watson, C.G., 1973. Monooxygenasecatalyzed metabolism of thioethers and selenoethers by Fungi. Phytochemistry 12(11), 2609-2611.

Balasubramanian, R., Smith, S.M., Rawat, S., Yatsunyk, L.A., Stemmler, T.L. and Rosenzweig, A.C., 2010. Oxidation of methane by a biological dicopper centre. Nature 465(7294), 115-U131.

Batt, A.L., Kim, S. and Aga, D.S., 2006. Enhanced biodegradation of iopromide and trimethoprim in nitrifying activated sludge. Environ. Sci. Technol. 40(23), 73677373.

Benjamini, Y. and Hochberg, Y., 1995. Controlling the False Discovery Rate - a Practical and Powerful Approach to Multiple Testing. J. Roy. Stat. Soc. Ser. B. (Stat. Method.) 57(1), 289-300.

Burke, V., Richter, D., Hass, U., Duennbier, U., Greskowiak, J. and Massmann, G., 2014. Redox-dependent removal of 27 organic trace pollutants: compilation of results from tank aeration experiments. Environ. Earth. Sci. 71(8), 3685-3695.

Dorival-Garcia, N., Zafra-Gomez, A., Navalon, A., Gonzalez-Lopez, J., Hontoria, E. and Vilchez, J.L., 2013. Removal and degradation characteristics of quinolone antibiotics in laboratory-scale activated sludge reactors under aerobic, nitrifying and anoxic conditions. J. Environ. Manage. 120, 75-83.

Falas, P., Andersen, H.R., Ledin, A. and Jansen, J., 2012. Impact of solid retention time and nitrification capacity on the ability of activated sludge to remove pharmaceuticals. Environ. Technol. 33(7-9), 865-872. 
Falas, P., Wick, A., Castronovo, S., Habermacher, J., Ternes, T.A. and Joss, A., 2016. Tracing the limits of organic micropollutant removal in biological wastewater treatment. Water Res. 95, 240-249.

Fernandez-Fontaina, E., Omil, F., Lema, J.M. and Carballa, M., 2012. Influence of nitrifying conditions on the biodegradation and sorption of emerging micropollutants. Water Res. 46(16), 5434-5444.

Gao, J.F., Luo, X., Wu, G.X., Li, T. and Peng, Y.Z., 2013. Quantitative analyses of the composition and abundance of ammonia-oxidizing archaea and ammonia-oxidizing bacteria in eight full-scale biological wastewater treatment plants. Bioresour. Technol. 138, 285-296.

Ginestet, P., Audic, J.M., Urbain, V. and Block, J.C., 1998. Estimation of nitrifying bacterial activities by measuring oxygen uptake in the presence of the metabolic inhibitors allylthiourea and azide. Appl. Environ. Microbiol. 64(6), 2266-2268.

Gulde, R., Helbling, D.E., Scheidegger, A. and Fenner, K., 2014. pH-dependent biotransformation of ionizable organic micropollutants in activated sludge. Environ. Sci. Technol. 48(23), 13760-13768.

Helbling, D.E., Hollender, J., Kohler, H.P., Singer, H. and Fenner, K., 2010. Highthroughput identification of microbial transformation products of organic micropollutants. Environ. Sci. Technol. 44(17), 6621-6627.

Helbling, D.E., Johnson, D.R., Honti, M. and Fenner, K., 2012. Micropollutant biotransformation kinetics associate with WWTP process parameters and microbial community characteristics. Environ. Sci. Technol. 46(19), 10579-10588. 
Hlavica, P. and Damani, L.A. (1991) $N$-oxidation of drugs : biochemistry, pharmacology, toxicology, Chapman \& Hall, London ; New York.

Hyman, M.R., Murton, I.B. and Arp, D.J., 1988. Interaction of Ammonia Monooxygenase from Nitrosomonas europaea with Alkanes, Alkenes, and Alkynes. Appl. Environ. Microbiol. 54(12), 3187-3190.

Jantti, H., Jokinen, S. and Hietanen, S., 2013. Effect of nitrification inhibitors on the Baltic Sea ammonia-oxidizing community and precision of the denitrifier method. Aquat. Microb. Ecol. 70(2), 181-186.

Jewell, K.S., Castronovo, S., Wick, A., Falas, P., Joss, A. and Ternes, T.A., 2016. New insights into the transformation of trimethoprim during biological wastewater treatment. Water Res. 88, 550-557.

Johnson, D.R., Helbling, D.E., Lee, T.K., Park, J., Fenner, K., Kohler, H.P. and Ackermann, M., 2015a. Association of biodiversity with the rates of micropollutant biotransformations among full-scale wastewater treatment plant communities. Appl. Environ. Microbiol. 81(2), 666-675.

Johnson, D.R., Helbling, D.E., Men, Y. and Fenner, K., 2015b. Can meta-omics help to establish causality between contaminant biotransformations and genes or gene products? Environ. Sci. (Camb) 1(3), 272-278.

Kassotaki, E., Buttiglieri, G., Ferrando-Climent, L., Rodriguez-Roda, I. and Pijuan, M., 2016. Enhanced sulfamethoxazole degradation through ammonia oxidizing bacteria co-metabolism and fate of transformation products. Water Res. 94, 111-119.

Khunjar, W.O., Mackintosh, S.A., Skotnicka-Pitak, J., Baik, S., Aga, D.S. and Love, N.G., 2011. Elucidating the relative roles of ammonia oxidizing and heterotrophic 
bacteria during the biotransformation of $17 \alpha$-Ethinylestradiol and Trimethoprim. Environ. Sci. Technol. 45(8), 3605-3612.

Kjeldal, H., Pell, L., Pommerening-Roser, A. and Nielsen, J.L., 2014. Influence of $p-$ cresol on the proteome of the autotrophic nitrifying bacterium Nitrosomonas eutropha C91. Arch. Microbiol. 196(7), 497-511.

Li, B. and Zhang, T., 2010. Biodegradation and adsorption of antibiotics in the activated sludge process. Environ. Sci. Technol. 44(9), 3468-3473.

Li, F., Jiang, B., Nastold, P., Kolvenbach, B.A., Chen, J., Wang, L., Guo, H., Corvini, P.F. and Ji, R., 2015. Enhanced transformation of tetrabromobisphenol a by nitrifiers in nitrifying activated sludge. Environ. Sci. Technol. 49(7), 4283-4292.

Limpiyakorn, T., Furhacker, M., Haberl, R., Chodanon, T., Srithep, P. and Sonthiphand, P., 2013. amoA-encoding archaea in wastewater treatment plants: a review. Appl. Microbiol. Biotechnol. 97(4), 1425-1439.

Luo, Y., Guo, W., Ngo, H.H., Nghiem, L.D., Hai, F.I., Zhang, J., Liang, S. and Wang, X.C., 2014. A review on the occurrence of micropollutants in the aquatic environment and their fate and removal during wastewater treatment. Sci. Total. Environ. 473-474, $619-641$.

MacPherson, I.S. and Murphy, M.E.P., 2007. Type-2 copper-containing enzymes. Cell. Mol. Life Sci. 64(22), 2887-2899.

Maeng, S.K., Choi, B.G., Lee, K.T. and Song, K.G., 2013. Influences of solid retention time, nitrification and microbial activity on the attenuation of pharmaceuticals and estrogens in membrane bioreactors. Water Res. 47(9), 3151-3162. 
Margot, J., Lochmatter, S., Barry, D.A. and Holliger, C., 2016. Role of ammoniaoxidizing bacteria in micropollutant removal from wastewater with aerobic granular sludge. Water Sci. Technol. 73(3), 564-575.

Martens-Habbena, W., Qin, W., Horak, R.E., Urakawa, H., Schauer, A.J., Moffett, J.W., Armbrust, E.V., Ingalls, A.E., Devol, A.H. and Stahl, D.A., 2015. The production of nitric oxide by marine ammonia-oxidizing archaea and inhibition of archaeal ammonia oxidation by a nitric oxide scavenger. Environ. Microbiol. 17(7), 22612274.

McCarty, G.W., 1999. Modes of action of nitrification inhibitors. Biol. Fert. Soils. 29(1), $1-9$.

Men, Y., Han, P., Helbling, D.E., Jehmlich, N., Herbold, C., Gulde, R., Onnis-Hayden, A., Gu, A.Z., Johnson, D.R., Wagner, M. and Fenner, K., 2016. Biotransformation of two pharmaceuticals by the ammonia-oxidizing Archaeon Nitrososphaera gargensis. Environ. Sci. Technol. 50(9), 4682-4692.

Petrie, B., Barden, R. and Kasprzyk-Hordern, B., 2015. A review on emerging contaminants in wastewaters and the environment: current knowledge, understudied areas and recommendations for future monitoring. Water Res. 72, 3-27.

Pomies, M., Choubert, J.M., Wisniewski, C. and Coquery, M., 2013. Modelling of micropollutant removal in biological wastewater treatments: A review. Sci. Total Environ. 443, 733-748.

Rasche, M.E., Hyman, M.R. and Arp, D.J., 1991. Factors limiting aliphatic chlorocarbon degradation by Nitrosomonas europaea: cometabolic inactivation of ammonia 
monooxygenase and substrate specificity. Appl. Environ. Microbiol. 57(10), 29862994.

Rattier, M., Reungoat, J., Keller, J. and Gernjak, W., 2014. Removal of micropollutants during tertiary wastewater treatment by biofiltration: Role of nitrifiers and removal mechanisms. Water Res. 54C, 89-99.

Roh, H., Subramanya, N., Zhao, F., Yu, C.P., Sandt, J. and Chu, K.H., 2009. Biodegradation potential of wastewater micropollutants by ammonia-oxidizing bacteria. Chemosphere 77(8), 1084-1089.

Rosenzweig, A.C. and Sazinsky, M.H., 2006. Structural insights into dioxygen-activating copper enzymes. Curr. Opin. Struct. Biol. 16(6), 729-735.

Sathyamoorthy, S., Chandran, K. and Ramsburg, C.A., 2013. Biodegradation and cometabolic modeling of selected beta blockers during ammonia oxidation. Environ. Sci. Technol. 47(22), 12835-12843.

Sauder, L.A., Peterse, F., Schouten, S. and Neufeld, J.D., 2012. Low-ammonia niche of ammonia-oxidizing archaea in rotating biological contactors of a municipal wastewater treatment plant. Environ. Microbiol. 14(9), 2589-2600.

Sayavedra-Soto, L.A., Hamamura, N., Liu, C.W., Kimbrel, J.A., Chang, J.H. and Arp, D.J., 2011. The membrane-associated monooxygenase in the butane-oxidizing Grampositive bacterium Nocardioides sp. strain CF8 is a novel member of the AMO/PMO family. Environ. Microbiol. Rep. 3(3), 390-396.

Shi, J., Fujisawa, S., Nakai, S. and Hosomi, M., 2004. Biodegradation of natural and synthetic estrogens by nitrifying activated sludge and ammonia-oxidizing bacterium Nitrosomonas europaea. Water Res. 38(9), 2322-2329. 
Skotnicka-Pitak, J., Khunjar, W.O., Love, N.G. and Aga, D.S., 2009. Characterization of metabolites formed during the biotransformation of 17alpha-ethinylestradiol by Nitrosomonas europaea in batch and continuous flow bioreactors. Environ. Sci. Technol. 43(10), 3549-3555.

Sun, Q., Li, Y., Chou, P.H., Peng, P.Y. and Yu, C.P., 2012. Transformation of bisphenol A and alkylphenols by ammonia-oxidizing bacteria through nitration. Environ. Sci. Technol. 46(8), 4442-4448.

Taylor, A.E., Vajrala, N., Giguere, A.T., Gitelman, A.I., Arp, D.J., Myrold, D.D., Sayavedra-Soto, L. and Bottomley, P.J., 2013. Use of Aliphatic n-Alkynes To Discriminate Soil Nitrification Activities of Ammonia-Oxidizing Thaumarchaea and Bacteria. Appl. Environ. Microbiol. 79(21), 6544-6551.

Tran, N.H., Urase, T. and Kusakabe, O., 2009. The characteristics of enriched nitrifier culture in the degradation of selected pharmaceutically active compounds. J. Hazard. Mater. 171(1-3), 1051-1057.

Wells, G.F., Park, H.D., Yeung, C.H., Eggleston, B., Francis, C.A. and Criddle, C.S., 2009. Ammonia-oxidizing communities in a highly aerated full-scale activated sludge bioreactor: betaproteobacterial dynamics and low relative abundance of Crenarchaea. Environ. Microbiol. 11(9), 2310-2328.

Yang, S.F., Lin, C.F., Wu, C.J., Ng, K.K., Lin, A.Y. and Hong, P.K., 2012. Fate of sulfonamide antibiotics in contact with activated sludge--sorption and biodegradation. Water Res. 46(4), 1301-1308.

Yi, T. and Harper, W.F., Jr., 2007. The link between nitrification and biotransformation of 17alpha-ethinylestradiol. Environ. Sci. Technol. 41(12), 4311-4316. 
Zhou, X. and Oleszkiewicz, J.A., 2010. Biodegradation of oestrogens in nitrifying activated sludge. Environ. Technol. 31(11), 1263-1269. 
Table 1. MPs whose biotransformation in NAS communities is reported to be inhibited by ATU.

\begin{tabular}{|c|c|c|c|c|c|c|c|}
\hline MP & $\begin{array}{c}\text { ATU } \\
\text { added } \\
\text { (mg/L) }\end{array}$ & $\begin{array}{l}\text { TSS } \\
(\mathrm{g} / \mathrm{L})\end{array}$ & $\begin{array}{l}\mathrm{NH}_{4}-\mathrm{N} \\
\text { added } \\
\text { (mg/L) }\end{array}$ & $\begin{array}{l}\text { MP conc. } \\
(\mu \mathrm{g} / \mathrm{L})\end{array}$ & $\begin{array}{c}I_{A T U} \\
\text { in reference } \\
\end{array}$ & $\begin{array}{c}I_{A T U}\left(I_{O C T}\right) \\
\text { in this study }\end{array}$ & Reference \\
\hline \multirow{4}{*}{ Ibuprofen } & 10 & 1 & 100 & 100 & 0.25 & \multirow{4}{*}{$0.03(0)$} & (Tran et al., 2009) \\
\hline & 10 & $1^{\mathrm{c}}$ & $70 / 140$ & 2000 & 0 & & (Roh et al., 2009) \\
\hline & 12 & $1.8-5.1$ & $<2 / 10 / 29$ & 100 & $0-0.47$ & & (Falas et al., 2012) \\
\hline & 11.1 & $2.5-4.7$ & 50 & 1 & 0 & & (Margot et al., 2016) \\
\hline \multirow{2}{*}{ Naproxen } & 10 & 1 & 100 & 100 & 0.6 & \multirow{2}{*}{0} & (Tran et al., 2009) \\
\hline & 11.1 & $2.5-4.7$ & 50 & 1 & 0.38 & & (Margot et al., 2016) \\
\hline \multirow{2}{*}{ Atenolol } & 30 & 1.73 & 20 & 15 & 0.63 & \multirow{2}{*}{$0.04(0.06)$} & $\left(\right.$ Sathyamoorthy et al., 2013) ${ }^{d}$ \\
\hline & 11.1 & $2.5-4.7$ & 50 & 1 & 0 & & (Margot et al., 2016) \\
\hline \multirow{2}{*}{ Bezafibrate } & 50 & $4-16$ & 20 & 1 & 0.48 & \multirow{2}{*}{$0.26(0.29)$} & (Maeng et al., 2013) \\
\hline & 11.1 & $2.5-4.7$ & 50 & 1 & 0.13 & & (Margot et al., 2016) \\
\hline \multirow{4}{*}{ Ketoprofen } & 5 & NA & $0-0.5$ & 2 & 0.76 & \multirow{4}{*}{$0.41(0.28)$} & (Rattier et al., 2014) \\
\hline & 10 & 1 & 100 & 100 & 0.57 & & (Tran et al., 2009) \\
\hline & 50 & $4-16$ & 20 & 1 & 0.75 & & (Maeng et al., 2013) \\
\hline & 11.1 & $2.5-4.7$ & 50 & 1 & 0.22 & & (Margot et al., 2016) \\
\hline \multirow{2}{*}{ Diclofenac $^{e}$} & 10 & 1 & 100 & 100 & 0.67 & \multirow{2}{*}{$0.97(0.58)$} & (Tran et al., 2009) \\
\hline & 50 & $4-16$ & 20 & 1 & 0.32 & & (Maeng et al., 2013) \\
\hline Furosemide & 5 & NA & $0-0.5$ & 2 & 0.78 & $0.79(0.33)$ & (Rattier et al., 2014) \\
\hline Indomethacin & 10 & 1 & 100 & 100 & 0.86 & $0.74(0.43)$ & (Tran et al., 2009) \\
\hline Irgarol & 11.1 & $2.5-4.7$ & 50 & 1 & 0.37 & $0.36(0.19)$ & (Margot et al., 2016) \\
\hline Terbutryn & 11.1 & $2.5-4.7$ & 50 & 1 & 0.53 & $0.44(0.14)$ & (Margot et al., 2016) \\
\hline \multirow{4}{*}{ Trimethoprim } & 5 & 3.3 & 50 & 250 & 0.64 & \multirow{4}{*}{$0.66(0.60)$} & (Batt et al., 2006) \\
\hline & 11.1 & $2.5-4.7$ & 50 & 1 & 0.5 & & (Margot et al., 2016) \\
\hline & 10 & NA & $\sim 24$ & 0.5 & 0 & & (Khunjar et al., 2011) \\
\hline & 5 & NA & $0-0.5$ & 2 & $<0$ & & (Rattier et al., 2014) \\
\hline \multirow{2}{*}{$\begin{array}{l}\text { Acetaminophen } \\
\text { (Paracetamol) }\end{array}$} & 50 & $0.75^{\mathrm{e}}$ & 52.5 & 1000 & 0.29 & NA & (De Gusseme et al., 2011) \\
\hline & 5 & NA & $0-0.5$ & 2 & 0.26 & NA & (Rattier et al., 2014) \\
\hline \multirow{2}{*}{ EE2 } & 10 & NA & $\sim 24$ & 0.5 & $\sim 0.5$ & NA & (Khunjar et al., 2011) \\
\hline & 50 & $4-16$ & 20 & 1 & 0.34 & NA & (Maeng et al., 2013) \\
\hline \multirow{3}{*}{ Gemfibrozil } & 5 & NA & $0-0.5$ & 2 & 0.7 & NA & (Rattier et al., 2014) \\
\hline & 50 & $4-16$ & 20 & 1 & 0.84 & NA & (Maeng et al., 2013) \\
\hline & 10 & 1 & 100 & 100 & 0.57 & NA & (Tran et al., 2009) \\
\hline lopromide & 5 & 3.3 & 50 & 250 & 0.11 & NA & (Batt et al., 2006) \\
\hline Ciprofloxacin & 10 & 7 & 100 & 500 & 0.4 & NA & (Dorival-Garcia et al., 2013) \\
\hline Piromidic acid & 10 & 7 & 100 & 500 & 0.55 & NA & (Dorival-Garcia et al., 2013) \\
\hline Norfloxacin & 10 & 7 & 100 & 500 & 0.43 & NA & (Dorival-Garcia et al., 2013) \\
\hline Pipemidie acid & 10 & 7 & 100 & 500 & 0.5 & NA & (Dorival-Garcia et al., 2013) \\
\hline Ofloxacin & 10 & 7 & 100 & 500 & 0.49 & NA & (Dorival-Garcia et al., 2013) \\
\hline Moxifloxacin & 10 & 7 & 100 & 500 & 0.63 & NA & (Dorival-Garcia et al., 2013) \\
\hline Triclosan & 10 & $1^{\mathrm{e}}$ & $70 / 140$ & 2000 & $0.3-0.5$ & NA & (Roh et al., 2009) \\
\hline \multirow{2}{*}{ Bisphenol A } & 10 & $1^{\mathrm{e}}$ & $70 / 140$ & 1000 & 0.4 & NA & (Roh et al., 2009) \\
\hline & 11.1 & $2.5-4.7$ & 50 & 1 & 0.74 & NA & (Margot et al., 2016) \\
\hline
\end{tabular}




\begin{tabular}{cccccccc} 
Clofibric acid & 10 & 1 & 100 & 100 & 0.17 & NA & (Tran et al., 2009) \\
\hline Fenoprofen & 10 & 1 & 100 & 100 & 0.67 & NA & (Tran et al., 2009) \\
\hline Propyphenazone & 10 & 1 & 100 & 100 & 0.75 & NA & (Tran et al., 2009) \\
\hline Carbamazepine & 10 & 1 & 100 & 100 & 0.63 & NA & (Tran et al., 2009) \\
\hline Lincomycin & 5 & NA & $0-0.5$ & 2 & 1 & NA & (Rattier et al., 2014) \\
\hline Caffeine & 5 & NA & $0-0.5$ & 2 & 0.38 & NA & (Rattier et al., 2014) \\
\hline $\begin{array}{c}\text { Pentoxifylline } \\
\text { Tetrabromo- } \\
\text { bisphenol A }\end{array}$ & 50 & $4-16$ & 20 & 1 & 0.37 & NA & (Maeng et al., 2013) \\
\hline lohexol & 50 & 1.5 & 50 & 1000 & 0.69 & NA & (Li et al., 2015) \\
\hline
\end{tabular}

${ }^{a}$ the extent of inhibition with ATU-treatment in the referred study.

butside of the parentheses is the extent of inhibition with ATU-treatment, and inside of the parentheses is the extent of inhibition with OCT-treatment in this study.

${ }^{c}$ VSS instead of TSS.

$\mathrm{d}$ a nitrification enrichment from NAS was used.

enot included in the 17 MPs with higher ATU inhibition due to its low removal (14\%) in ATU-untreated control in this study. 


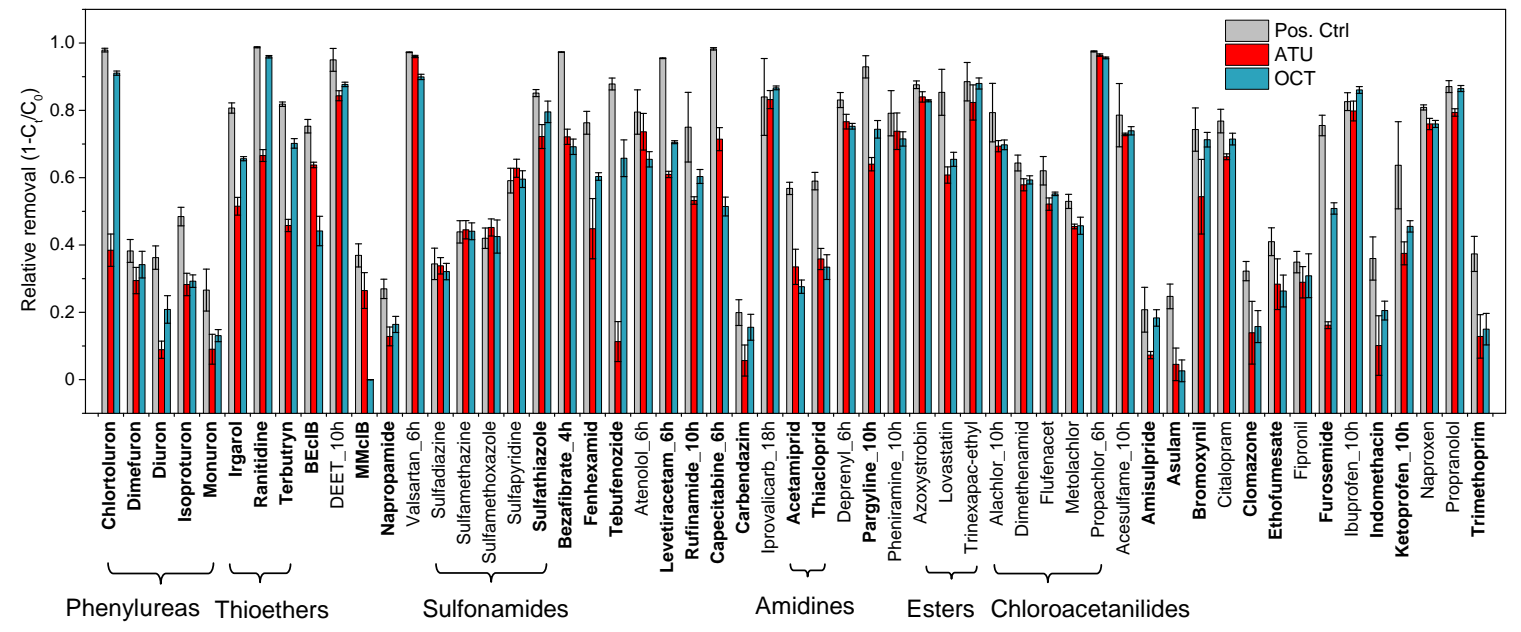

Figure 1. The 55 MPs with a removal $>20 \%$ in positive control reactors and their removals in ATU- and OCT- treated reactors (MPs in bold are the ones with an extent of inhibition $I>0.2$ by either ATU or OCT; removals were at $46 \mathrm{~h}$ unless specified otherwise). 


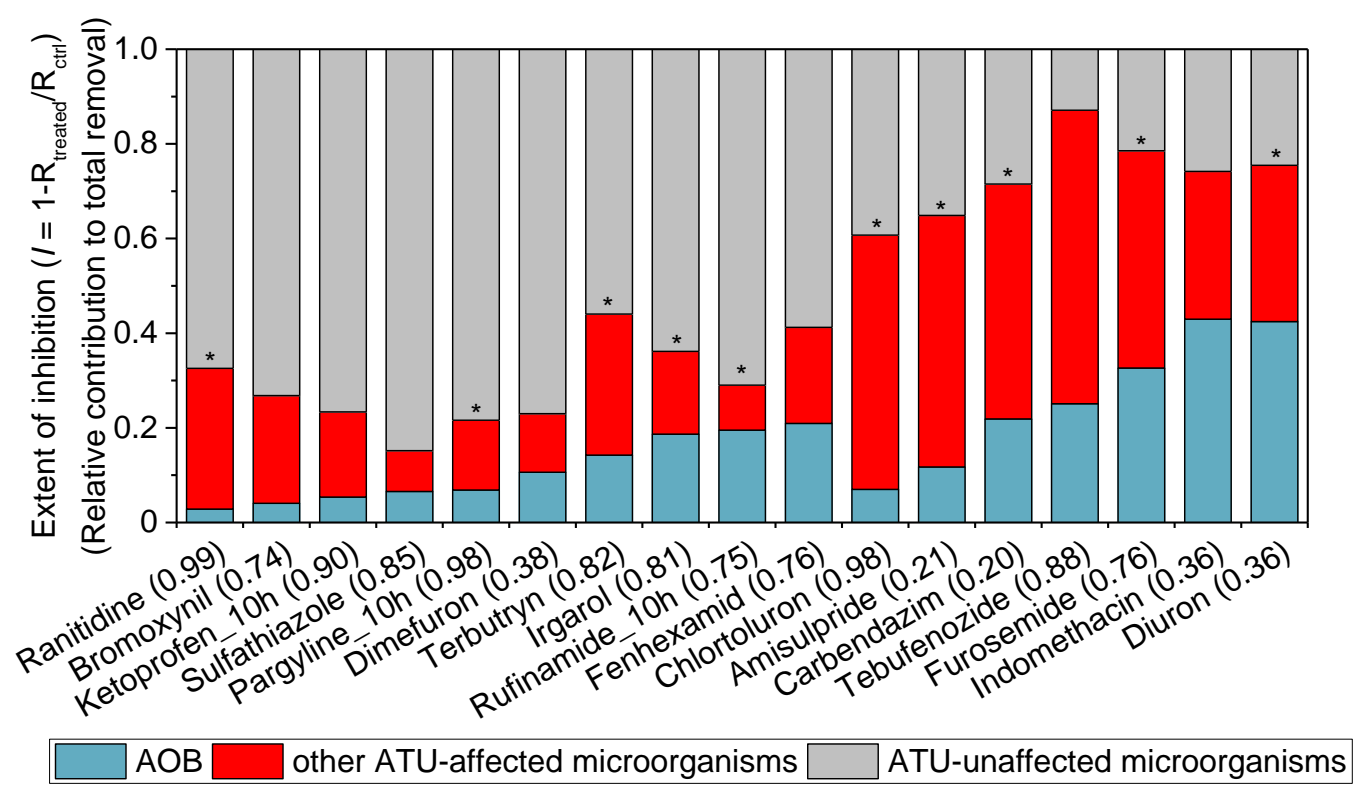

Figure 2. The 17 MPs with > 1.5-fold higher inhibition by ATU than by OCT (the extent of inhibition $I$ was calculated using average removals of triplicate samples, blue bars represent $I_{O C T}$, the sum of blue and red bars represent $I_{A T U}$; $*$ represents significant difference between removals of ATU- and OCT- treated samples by student t-test with Benjamini and Hochberg procedure, FDR $<0.05$; the number in parentheses is the removal in the untreated control at $46 \mathrm{~h}$ unless specified). 


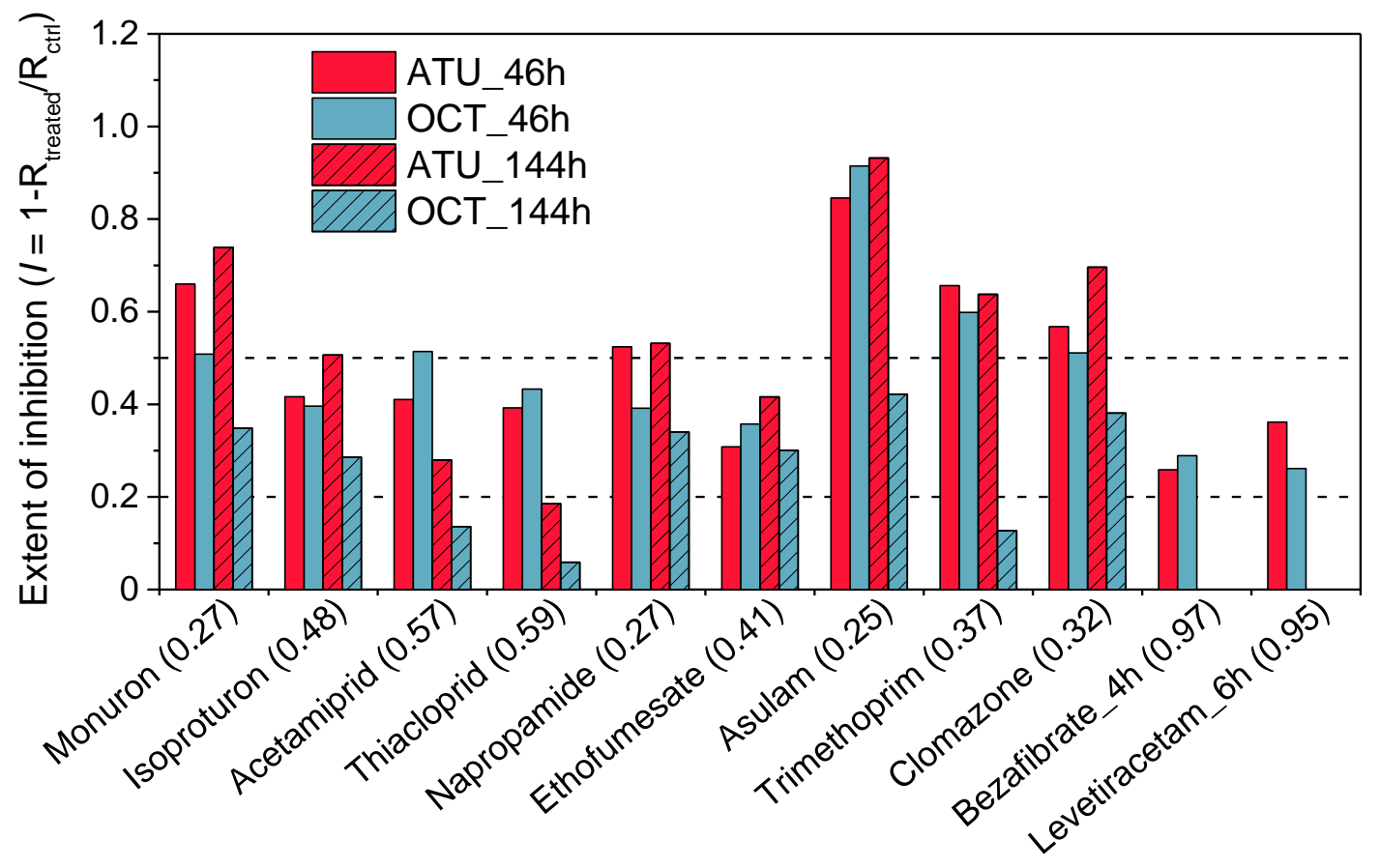

Figure 3. MPs with similar inhibition by ATU and OCT at $46 \mathrm{~h}$ and decreasing inhibition by OCT at $144 \mathrm{~h}$ (the extent of inhibition $I$ was calculated using average removals of triplicate samples; the number in parentheses is the removal in untreated control at $46 \mathrm{~h}$ unless specified; dashed line indicates 50\% and 20\% inhibition, respectively). 

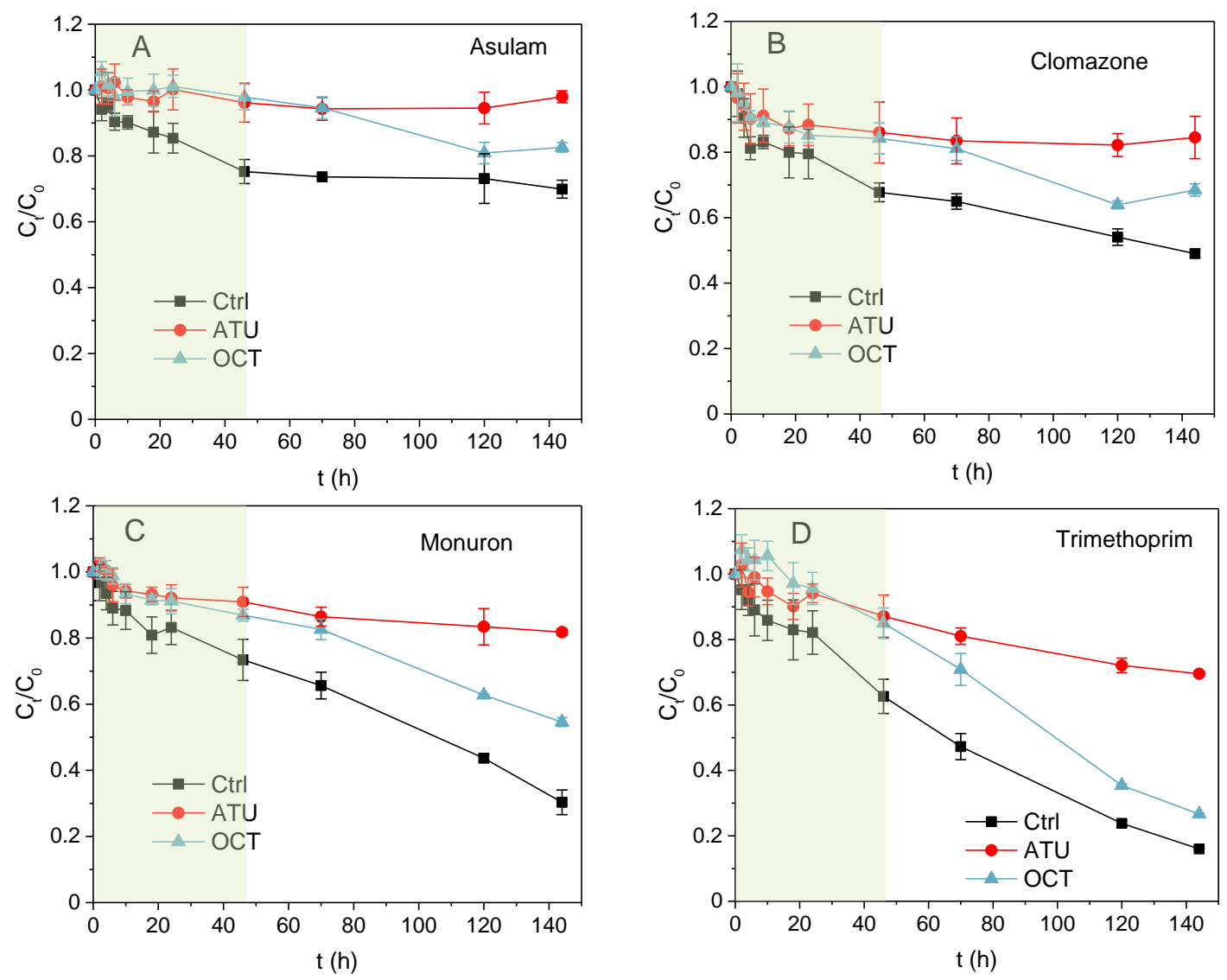

Figure 4. Biotransformation of asulam (A), lomazone (B), monuron (C), and trimethoprim (D) (Shaded area indicates time when ammonia oxidation was completely inhibited by both ATU and OCT; clear area indicates time when ammonia oxidation activity started to recover in OCTtreated samples). 
Graphical Abstract

Graphical Abstract

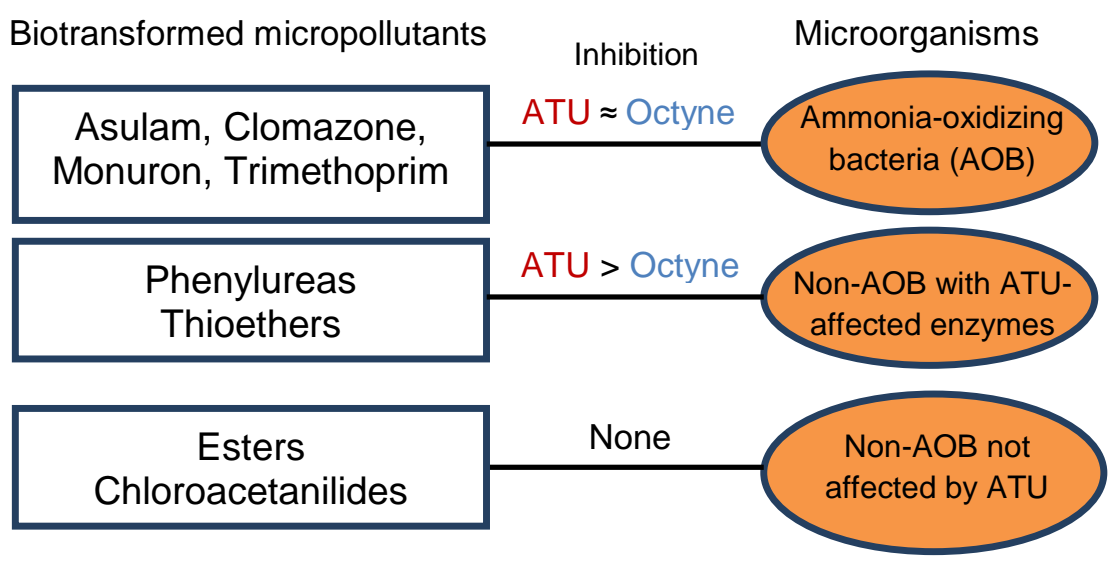

